\title{
ERRATUM
}

doi:10.1038/nature06511

\section{The effects of molecular noise and size control on variability in the budding yeast cell cycle}

Stefano Di Talia, Jan M. Skotheim, James M. Bean, Eric D. Siggia \& Frederick R. Cross

Nature 448, 947-951 (2007)

In Fig. $1 \mathrm{~b}$ of this Letter, the two labels 'S/G2/M' were inadvertently misplaced. The corrected Fig. $1 \mathrm{~b}$ (in black and white) is shown below.

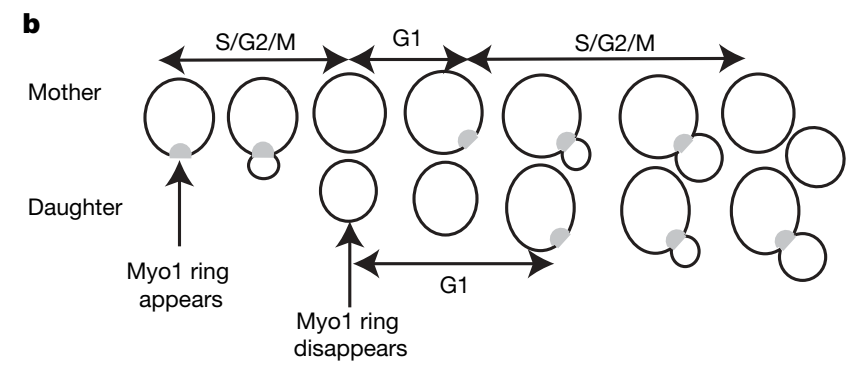

